\title{
OVIPOSITION INDUCED BY THE MALE IN PIGEONS
}

\author{
WALLACE CRAIG \\ Department of Philosophy, Umiversity of Maine
}

The influence of the male upon the time of oviposition is a matter in regard to which pigeons differ from some other birds, notably the domestic fowl. With regard to the fowl I have consulted a number of pouitry keepers and experts, chiefly Dr. Raymond Pearl and Dr. Frank M. Surface, of the Maine Agricultural Experiment Station, where the most extensive studies of the egglaying of fowls have been, and are being carried on. Dr. Pearl and Dr. Surface tell me that the domestic hen, and also the hen of the wild Gallus bankiva so far as can be ascertained, commence their spring laying at an approximately fixed date which can neither be deferred by withholding the cock nor advanced by giving the cock before the usual time.

Pigeons differ widely from poultry in this respect. If, from the winter season onward, an old female piegon be kept unmated and isolated, she refrains from egg-laying, in evident distress for want of a mate, until the breeding season is far advanced; at length she does begin to lay, but her laying without a mate manifestly partakes of the abnormal. And a virgin pigeon, if kept isolated from other pigeons, may postpone her laying for a still longer period. On the other hand, a female pigeon, young or old, will lay very early in the season if she be early mated. Moreover, there is a pretty definite interval between the first copulation and the laying of the first egg, namely six or seven days; if the egg be delayed much beyond this time, the fact indicates some indisposition on the part of the female. And as the pair rear brood after brood throughout the season, this time-relation between copulation and egg-laying is regularly repeated. 
The utility of this time adjustment in pigeons seems obvious. The male pigeon takes his turn daily in the duty of incubation: hence the female must not lay the eggs before he is ready to sit. This aspect of the matter, which has to do with pigeon sociology, has already been treated elsewhere (Craig '08) and will be discussed more fully in a book dealing with pigeon behavior. The present paper is to show, not why the male should determine the time of oviposition, but how he does determine it.

The thesis of the present paper is, that the influence of the male in inducing oviposition is a psychological influence; that the stimulus to oviposition is not the introduction of sperm, for the male can cause the female to lay even though he does not copulate with her. This is easily proven by an experiment, which requires only pigeons, patience, and time, and I shall now recount seven repetitions of such experiment, the first two being accidental cases, the other five being trials designed and carried out on purpose to test the thesis.

Case 1 (1903). In the spring of 1903 I brought together a virgin female dove (individual female no. 7 , the species in all these trials being the blonde ring-dove, Turtur risorius) and a young inexperienced male, intending simply that they should mate in the normal manner. The young male played up to the female, but due to his inexperience and to other causes which need not be discussed here, his mating behavior was imperfect and he did not copulate with her. Nevertheless, in due time (six days) she laid an egg, and a second egg, as usual, forty hours later. This was the first intimation to me that a male bird can stimulate the female to lay, without copulating with her. Such an explanationseemed so absurd at that time that I dismissed it with the assumption that the birds must have copulated unobserved, and I did not even test the eggs to see if they were fertile. Looking back on that case now, however, and considering the observed behavior of that male, I feel reasonably certain that he did not fertilize the eggs but simply stimulated oviposition through the psychic (neural) channels.

Case 2 (1904). A female dove (no. 5) had been kept alone ever since her mate had died in November, 1903, and as time wore on 
she showed intense anxiety to mate. She being a very tame bird, I had often caught and held her gently, but she did not like to be held, so one day in early March I tried tickling her head and pulling the feathers about her neck somewhat as a courting male would do it, and, finding that the poor lonely bird received these attentions with intense pleasure and became still more tame, I continued to preen her neck daily. She now acted toward the hand as if it were a mate, went through a nesting performance in her seed dish, there being no nest in her cage, and to my astonishment laid her eggs in due season. The first egg was laid March 11 and the second March 13. There is no doubt in my mind that the caressing of this bird's head and neck brought on oviposition. I once tried to repeat the experiment with another female dove, but she would not accept the touch of the hand as the former dove had done. Yet there is other evidence indicating that, with a specially tamed bird, this experiment, inducing oviposition by the hand, could be successfully repeated.

This case called to mind that of 1903 , and suggested an experiment to determine definitely whether the male dove can stimulate the female to lay, without actual copulation. Opportunity to try this experiment was not found till 1907 and following years, when it was planned as follows.

\section{Method of the regular trials}

The experiment requires an unmated female dove that is not laying eggs, preferably a young dove that has never laid. It is best tried early in the season (e.g., in February), especially if an old dove be used, for, as said above, if the female is kept too long without a mate she may lay without one. Side by side with this female, in a separate cage, is placed an unmated male, and the two are given several days to become acquainted. When they act toward one another like mate and mate, the doors separating them are opened and they are allowed to come together for a time, under constant supervision. When they attempt to copulate, a slender rod which can be thrust between the bars of the cage is used to keep them apart. Such attempts are made many times in a day, 
mostly in the afternoon, and are continued for several days in succession; hence it is best that the experimenter should be able to devote some hours a day for several days in succession to a single pair or at most two pairs of birds. Whenever the birds are not under surveillance they are shut apart, each in his or her own cage. But they should be allowed to come together daily until the egg is laid.

A factor which caused difficulty in one of my trials was the nest. In cases 1, 2, 3 and 6, the bird laid without any nest at all (except that in case 6 a nest was given just a few hours before the egg was deposited). But in case 4 (q.v.) the female refused to lay without a nest: it was then necessary to remove the male and make the trial again, first giving the female a nest, and waiting long enough to prove that the nest alone would not cause her to lay.

\section{Results of the regular trials}

Case 3 (1907). Female dove, no. 20. This bird had been bought recently from a dealer, and it was not known whether she had laid earlier in the season. But she was kept isolated for some time, during which she showed no inclination to lay. She was then given a male in the manner indicated. No nest given.

June 9. Male allowed in cage of female, and plays up to her.

June 15. First egg.

June 17. Second egg. (The second egg was of no special interest. After the first egg was laid, I generally left the doors open, allowing the pair to come together without surveillance.)

Case 4 (1908). Female, the same. She had not laid since the close of last season. No nest given.

February 4. Male allowed to enter.

The female was unresponsive and showed by her behavior that this time she was holding back for want of a nest. This deficiency was supplied in the following manner (vide ut supra.)

February 8. Male taken away to another building.

March 10. Nest put in cage. Female paid practically no attention to it. Many days were allowed to pass, in order to make sure that the nest alone would not stimulate the female to lay. 
March 21. Male (after short period in sight of female, that they might become re-acquainted) allowed to enter.

March 27. Egg laid.

Case 5 (1910). Female, the same as in cases 3 and 4 . She has laid no eggs since last season (1909.)

January 20 . I begin to allow male in cage, at same time putting nest in.

January 29. Egg laid.

Case 6 (1908). Female, no. 19. Virgin, has never laid. No nest given. In this case, the date on which the female was first given the requisite stimulus cannot be stated so definitely as in the other cases.

July 12. Male, in his cage, placed close to cage of female. Cooing commences. Female so excited that she several times assumes, and maintains in extreme degree, the copulation posture.

July 14. Male allowed into cage of female, but he fights her, so that it is necessary to remove him (otherwise the female might be painfully injured), and to allow the pair a few days more of preliminary acquaintanceship.

July 18. Male allowed to begin his series of daily visits.

July 22. Egg laid.

Case 7 (1910). Female no. 19, the same as in case 6. She has laid no eggs since last summer (1909.)

For several days before contact with the male, a nest was kept in her cage; but she paid no attention to it, showing that the nest alone would not stimulate her to lay.

January 20. Male allowed to enter.

January 26. Egg laid.

\section{SUMMARY}

1. In six cases, stimulation of a female dove by a male, without copulation, was followed by oviposition; and in one other instance (case 2), stimulation by the hand of man in imitation of a male dove was followed by oviposition

2. In six of the seven cases (being all except case 3 , in which the previous history was unknown), it was known that the female 
had laid no eggs previously during the current year. In two of these six cases the dove was a virgin and had never laid.

3. It is true that the female may, if left without a mate, begin to lay late in the season. Hence it might be suspected that the sequence of stimulation and egg-laying in the seven cases was mere coincidence. But this is precluded, first of course by the fact that coincidences are not known to happen seven times in succession, and further by the following considerations.

4. In some of the trials it was proven that the female when stimulated by the male laid much earlier in the season than she did when not so stimulated. This is shown in the following table.

Female, no. 20.

1908. (Case 4), stimulated by male, laid March 27.

1909. (Control), without male, began to lay May 13.

1910. (Case 5), stimulated by male, laid January 29.

Female, no. 19.

1909. (Control), without male, began to lay April 26.

1910. (Case 7), stimulated by male, laid January 26.

5. The interval between the first stimulation by the male, and the laying of the first egg, was as follows:

Case 1. 6 days.

Case 2. (Male not used.)

Case 3. 7 days.

Case 4. 6 days.

Case 5. 9 days.

Case 6. 4 to 10 days, depending on what is regarded as the first stimulation in this case.

('ase 7. 6 days.

The average and the variation of these intervals tally closely with the average and the variation of the interval in normal breeding, between the first copulation and the laying of the first egg.

6. There were no exceptions. Ovoposition never failed to follow within nine days after the first contact with the male. (The only partial failure was that of the first trial in case 4 , which was due to faulty experimental conditions.) 


\section{CONCLUSION}

These facts make it certain that the male dove can stimulate the female to lay, without copulating with her.

Harper ('04) mentioned the fact that ovulation in the pigeon does not take place until after the bird is mated, but he was in doubt as to how far the influence of mating was a 'mental'one and how far it was a matter of the introduction of sperm. The present paper goes to show that the stimulus to the whole process of egg development and laying is a psychic (neural) stimulus, not dependent upon the introduction of sperm.

\section{BIBLIOGRAPHY}

Craig, Wallace 1908 The voices of pigeons regarded as a means of social control. Am. Jour. Sociol., vol. 14, pp. 86-100.

Harper, Eugene Howard 1904 The fertilization and early development of the pigeon's egg. Am. Jour. Anat., vol. 3, pp. 349-386. 